\title{
Moderate Hypofractionation in Patients with Low-risk Prostate Cancer: Long-term Outcomes
}

\author{
MAURIZIO VALERIANI ${ }^{1}$, PIERLUIGI BONFILI ${ }^{2}$, CHIARA REVERBERI $^{1}$, LUCA MARINELLI $^{1}$, \\ LETIZIA FERELLA ${ }^{2}$, GIUSEPPE MINNITI ${ }^{3}$, VITALIANA DE SANCTIS ${ }^{1}$, MATTIA FALCHETTO OSTI ${ }^{1}$, \\ PAOLO BONOME ${ }^{1}$, LIDIA TRONNOLONE ${ }^{1}$, EMILIA VARRASSI ${ }^{2}$, GIOVANNI LUCA GRAVINA ${ }^{2}$, \\ PIETRO FRANZESE ${ }^{2}$, VINCENZO TOMBOLINI ${ }^{4}$ and MARIO DI STASO ${ }^{2}$ \\ ${ }^{1}$ Department of Radiation Oncology, S. Andrea Hospital, Sapienza University of Rome, Rome, Italy; \\ ${ }^{2}$ Department of Radiation Oncology, S. Salvatore Hospital, University of L'Aquila, L'Aquila, Italy; \\ ${ }^{3}$ Istituto di Ricovero e Cura a Carattere Scientifico (IRCCS) Neuromed, Pozzilli, Italy; \\ ${ }^{4}$ Department of Radiation Oncology, Policlinico Umberto I Hospital, Sapienza, University of Rome, Rome, Italy
}

\begin{abstract}
Background/Aim: To evaluate outcomes in patients with low-risk prostate cancer treated with hypofractionated radiotherapy (HyRT). Patients and Methods: Between April 2004 and December 2015, 175 patients with low-risk prostate cancer were treated with HyRT 60 Gy in 20 fractions with or without image guidance and reduction of margin from clinical target volume to planning target volume. Results: The median follow-up was 66 months. The 8-year overall survival for the whole patient cohort was $88.9 \%$. The 8-year biochemical no evidence of disease was higher in patients treated with imageguided HyRT (98.8\% vs. 88\%, p=0.023). During treatment, patients treated with image-guided HyRT presented a lower rate of grade 1-2 gastrointestinal toxicity $(25.3 \%$ vs. $42.2 \%$, $p=0.001)$. At the last follow-up, the grade 1 Gastro-intestinal toxicity rate was $4.0 \%$ and the grade 1-2 genito-urinary toxicity rate was $25.1 \%$. Conclusion: Our study demonstrated the efficacy of the schedule used with a low rate of acute and late toxicities. Therefore, reduction of margins with imageguided HyRT is safe.
\end{abstract}

Radiotherapy is a curative option for localized prostate cancer. Conventional treatment consists of administration of 70-81 Gy in 8-9 weeks. Dose escalation has demonstrated better outcomes in patients with localized prostate cancer treated with standard dose per fraction (1-4) at the expense of prolonging overall treatment time.

Correspondence to: Maurizio Valeriani, Radiation Oncology Department, Sant'Andrea Hospital, Via di Grottarossa 1035-1039, 00189 Rome, Italy. Tel: +39 0633776160, Fax: +39 0633776608, e-mail: mauval1@libero.it

Key Words: Hypofractionation, low-risk prostate cancer, imageguided radiotherapy.
Prostate cancer, in contrast to the majority of tumors, seems to have a low $\alpha / \beta$ ratio $(5,6)$, which is smaller than 3 Gy reported for late toxicity of rectum (7). Hypofractionation, using a higher dose per fraction with fewer fractions, may increase biological effectiveness and improve results, with similar or lower incidence of late toxicity. Moreover, technological advantages, as imageguided radiotherapy, have improved treatment accuracy making possible reduction of margin from Clinical target volume (CTV) to planning target volume (PTV) thus reducing toxicities. Recently hypofractionated RT has become an alternative strategy of treatment, demonstrating a good safety profile (8-10), but not increased efficacy (11-13).

In addition to a possible radiobiological benefit, hypofractionated RT reduces the number of patien visits to hospital, lowering the cost/time for the health system and for the patients. Based on these considerations, in 2004 we started a prospective multi-institutional study treating patients with low-risk prostate cancer with 60 Gy in 20 fractions over 4 weeks and here we retrospectively analyzed results in terms of survival and toxicities.

\section{Patients and Methods}

Patient characteristics. Between April 2004 and December 2015, 185 patients with intraprostatic $(\leq \mathrm{T} 2 \mathrm{c})$, Gleason score $\leq 6$ and prostate-specific antigen (PSA) $\leq 10 \mathrm{ng} / \mathrm{ml}$, biopsy-proven prostate cancer were treated with HyRT. Ten patients were lost to follow-up, therefore 175 patients were analyzed. Eighty-five patients $(48.6 \%)$ underwent image-guided HyRT and 90 (51.4\%) HyRT without image guidance. The median patient age at diagnosis was 73 years (range $=48-83$ years).

Pre-treatment evaluation included: digital-rectal examination, complete physical examination, PSA level, complete blood counts and standard biochemistry tests, bone scan, total body contrastenhanced computed tomography (CT). Patients treated after January 2008 also underwent contrast enhanced magnetic resonance imaging 
(MRI) with T2 weighted, diffusion and perfusion sequences. Median PSA at diagnosis was $6.4 \mathrm{ng} / \mathrm{ml}$ (range=2.4-9.5 ng/ml). The Internal Review Board approved this study (Protocol number 016/04). All patients provided written informed consent for participation and use of data. Patient characteristics are summarized in Table I.

Treatment. All patients underwent a pre-treatment CT planning (2.5 $\mathrm{mm}$ slice thickness) in the supine position with foot rests. The preparation for CT scan encompassed the administration of a mini enema for rectal emptying. Then patients were invited to urinate and to drink $500 \mathrm{ml}$ of water half an hour before the start of the procedure to fill the bladder. Planning CT images were fused with MRI images (Apparent Diffusion Coefficient (ADC) map, perfusion series and axial high resolution $\mathrm{T} 2$-weighting), when available, using automatic matching to help CTV delineation.

The CTV included the prostate and the first centimeter of the seminal vescicles. The PTV was generated adding a $5 \mathrm{~mm}$ isometric margin for patients treated with image-guided HyRT and $8 \mathrm{~mm}$ in all directions except in the posterior $(6 \mathrm{~mm})$ for patients treated with simple HyRT. The whole rectum from the anus to the sigmoid flexure, bladder, femoral heads and penile bulb were delineated as organs at risk. A 3D conformal plan was performed using five coplanar fields. Treatment was delivered by a linear accelerator using 6-15 MV photons. Thus, the PTV received $60 \mathrm{~Gy}$ in 20 fractions ( 3 Gy per fraction). According to the linear quadratic model, the HyRT regimen was biologically equivalent to $77.1 \mathrm{~Gy}$ in $2 \mathrm{~Gy}$ per fraction assuming an $\alpha / \beta$ ratio of $1.5 \mathrm{~Gy}$. This regimen was also equivalent to $72 \mathrm{~Gy}$ in 2 Gy fractions assuming an $\alpha / \beta$ ratio of 3 Gy for late responding tissue. Dose-volume constraints were as follows: V50 $<35 \%$ and V58 $<25 \%$ for the rectum; V43 $<50 \%$ for the bladder. Prior to each treatment, patients submitted to image-guided HyRT underwent a kilo-voltage cone-beam CT that was compared with the planning CT to verify the correct position. The patient's position was adjusted with an initial automatic bone alignment, followed by a soft-tissue alignment using the prostaterectum interface. Patients treated with HyRT underwent electronic portal imaging for the first 3 days consecutively, then weekly. From the start of RT, all patients were advised to follow a low-fiber and low-fat diet and to consume a cranberry-based supply and lactic ferment once daily.

Toxicity and follow-up. Patients were submitted to weekly evaluation of acute toxicity during treatment. First follow-up was performed at 2 months after the end of therapy, then every 2-3 months for the first year and every 6 months for the next 4 years, thereafter annually. Toxicities were assessed at each follow-up according to the Radiation Therapy Oncology Group (RTOG) scale for acute and late adverse effects (14). Acute toxicities were evaluated during treatment (as the worst grade documented at any time) and at 2 months after the end of therapy. Late toxicity, defined as toxicity occurred 90 days after RT completion, was analyzed at 6 months after the end of therapy and at the last follow-up.

Statistical analysis. The biochemical failure was defined as the PSA nadir plus $2 \mathrm{ng} / \mathrm{ml}$ according to the Phoenix criteria (15). Overall survival (OS), cancer-specific survival (CSS), biochemical no evidence of disease (bNED), disease-free survival (DFS) and metastasis-free survival (MFS) were calculated to the event using the Kaplan-Meier method. CSS events included death from primary disease, patients who died from other causes were considered alive
Table I. Patient characteristics.

\begin{tabular}{|c|c|c|c|c|c|c|}
\hline \multirow[t]{3}{*}{ Characteristic } & \multicolumn{4}{|c|}{ HyRT } & & \\
\hline & \multicolumn{2}{|c|}{$\begin{array}{l}\text { With image } \\
\text { guidance }\end{array}$} & \multicolumn{2}{|c|}{ Without } & \multicolumn{2}{|c|}{ Total } \\
\hline & $\mathrm{n}$ & $\%$ & n. & $\%$ & $\mathrm{n}$. & $\%$ \\
\hline \multicolumn{7}{|l|}{ Age } \\
\hline$<70$ years & 17 & 18.9 & 28 & 32.9 & 45 & 25.7 \\
\hline$\geq 70$ years & 73 & 81.1 & 57 & 67.1 & 130 & 74.3 \\
\hline \multicolumn{7}{|c|}{ PSA at diagnosis $(\mathrm{ng} / \mathrm{ml})$} \\
\hline $0.1-5$ & 26 & 28.9 & 23 & 27.1 & 49 & 28.0 \\
\hline $5.1-9.9$ & 64 & 71.1 & 62 & 72.9 & 126 & 72.0 \\
\hline \multicolumn{7}{|l|}{ T Stage } \\
\hline $\mathrm{T} 1 \mathrm{c}$ & 65 & 72.2 & 31 & 36.5 & 96 & 54.9 \\
\hline $\mathrm{T} 2 \mathrm{a}$ & 16 & 17.8 & 27 & 31.8 & 43 & 24.6 \\
\hline $\mathrm{T} 2 \mathrm{~b}$ & 2 & 2.2 & 13 & 15.2 & 15 & 8.5 \\
\hline $\mathrm{T} 2 \mathrm{c}$ & 7 & 7.8 & 14 & 16.5 & 21 & 12.0 \\
\hline
\end{tabular}

HyRT: Hypofractionated radiotherapy; PSA: prostatic-specific antigen.

at the date of death. DFS events included any type of disease progression (biochemical, local and metastatic). Biochemical-free survival was calculated considering patients who died from causes not related to their disease as censored. Differences in the incidence of acute and late toxicities between the two groups (image-guided HyRTG vs. HyRT) were evaluated with chi-square test. Median follow-up time was calculated with Kaplan-Meier estimate of time to date of last follow-up, considering death as censoring event. Statistical analysis was computed using SPSS statistical software package version 22.0 (IBM Corp. Armonk, NY, USA). $p$-Values lower than 0.05 were considered statistically significant.

\section{Results}

Survival and relapse. The median actuarial follow-up was 66 months $(95 \%$ confidence interval $=59.7-72.3$; range $=17-157$ months). The median PSA value at first follow-up was 1.24 $\mathrm{ng} / \mathrm{ml}$ (range $=0.02-9.1 \mathrm{ng} / \mathrm{ml}$ ), and at the last follow-up was $0,36 \mathrm{ng} / \mathrm{ml}$ (range $=0.01-10.5 \mathrm{ng} / \mathrm{ml})$.

The 5- and 8-year OS rates for the whole cohort were $95.8 \%$ and $88.9 \%$, respectively. No statistical difference was observed for patients treated with or without image guidance $(p=0.150)$. The 5- and 8-year CSS rates were $100 \%$ and $95.4 \%$, respectively. Eleven patients $(6.3 \%)$ died, nine $(5.1 \%)$ from causes not related to prostatic disease and two $(1.1 \%)$ from their disease after 64 and 95 months from HyRT completion. The 5- and 8-year bNED (Figure 1) were both 93.2\%. Nine patients $(5.1 \%)$ presented biochemical recurrence after a median of 37 months (range $=3-52$ months). The 5- and 8-year bNED for patients treated with image-guided HyRT were both $98.8 \%$, while those for patients treated with simple HyRT were both $88 \%$ ( $p=0.023$ ) (Figure 2). Five out of nine patients with biochemical progression developed clinical 


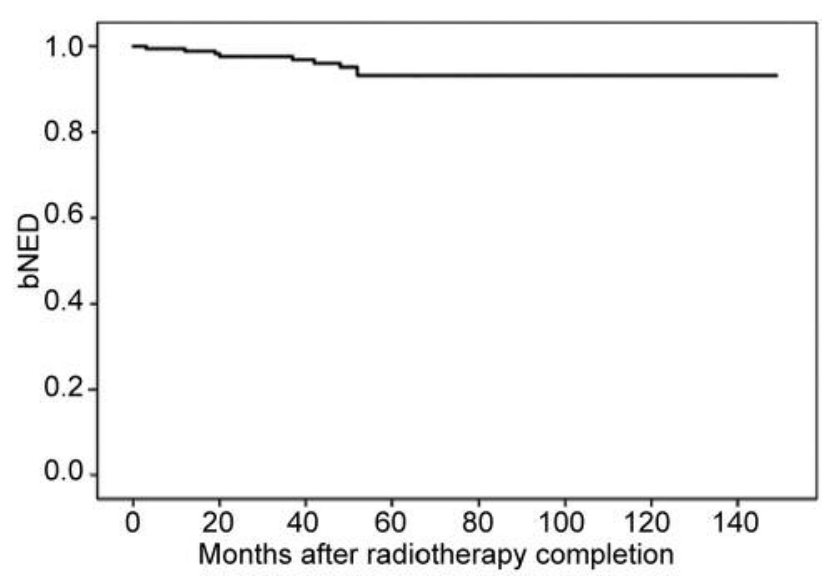

Figure 1. Biochemical no evidence of disease (bNED) for the whole patient cohort (175 patients).

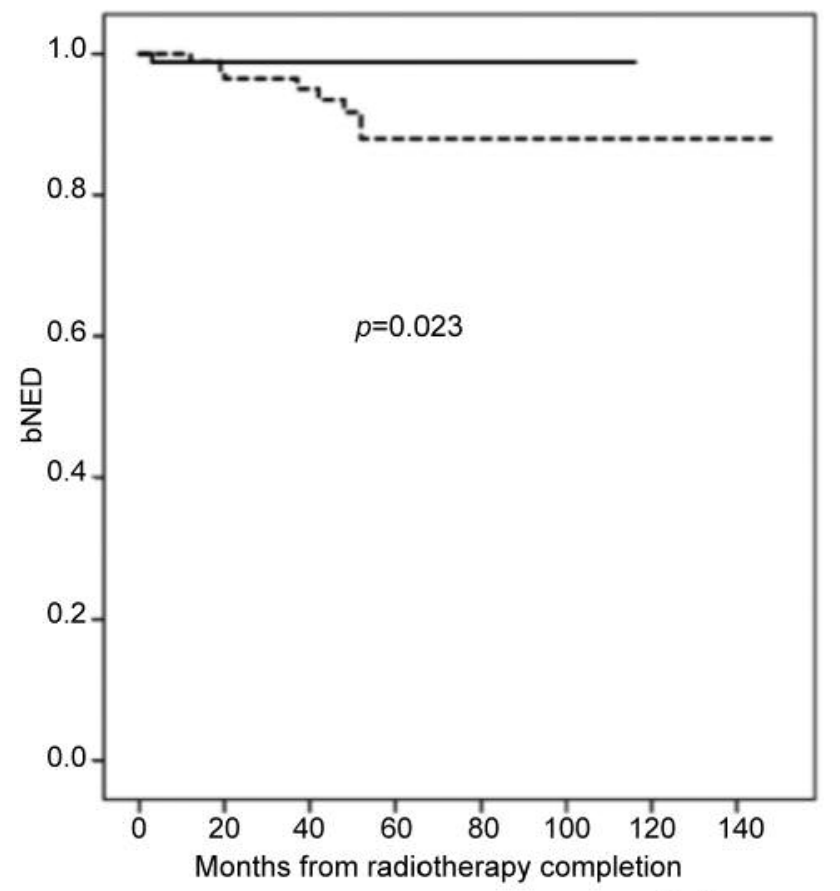

Guidance

No guidance

Figure 2. Biochemical no evidence of disease (bNED) for patients treated with hypofractionated radiotherapy with and without image guidance.

locoregional disease after a median of 64 months (range=29114 months). Two out of five patients with clinical locoregional disease developed metastatic progression after 53 and 67 months. The 5- and 8-year rates DFS for the whole

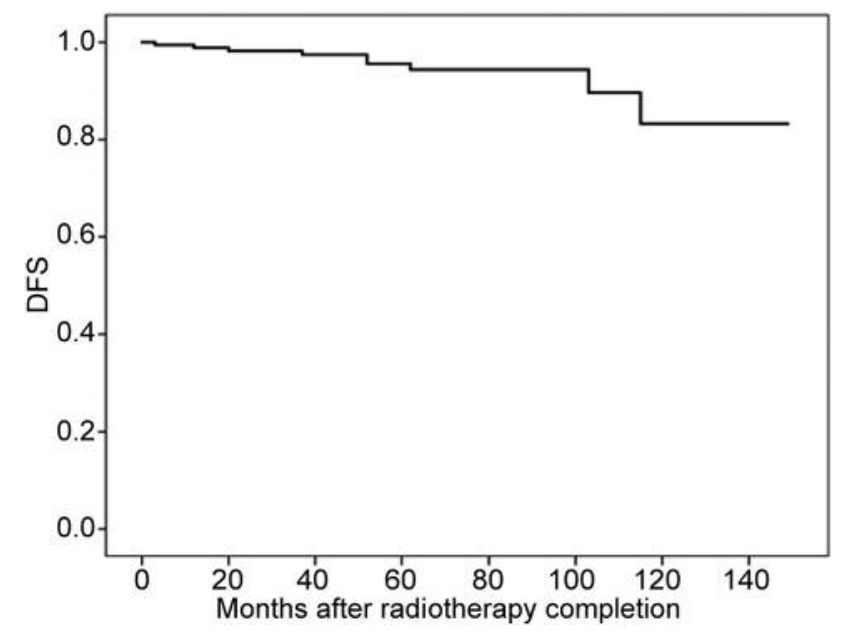

Figure 3. Disease-free survival (DFS) for the whole patient cohort (175 patients).

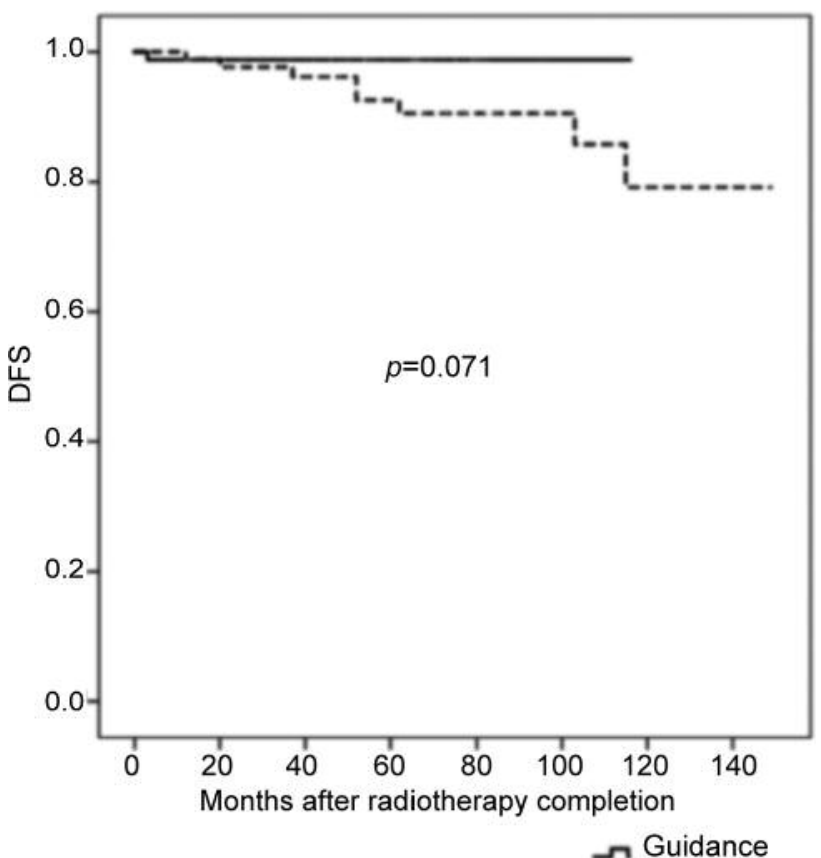

Figure 4. Disease-free survival (DFS) for patients treated with hypofractionated radiotherapy with and without image guidance.

cohort were $95.6 \%$ and $94.4 \%$, respectively (Figure 3 ); those for patients treated with image-guided HyRT were both $98.8 \%$, and for those treated with simple HyRT were $90.5 \%$ and $79.2 \%$, respectively ( $p=0.071$ ) (Figure 4$)$. The 5- and 8- 
Table II. Comparison of grade 1-2 gastro-intestinal (GI) and genito-urinary (GU) toxicities in the group treated with hypofractionated radiotherapy with and without image guidance.

\begin{tabular}{|c|c|c|c|c|c|c|c|c|c|c|}
\hline \multirow{3}{*}{ Toxicity } & \multicolumn{5}{|c|}{ GI } & \multicolumn{5}{|c|}{ GU } \\
\hline & \multicolumn{2}{|c|}{ With guidance } & \multicolumn{2}{|c|}{ Without } & \multirow[t]{2}{*}{$p$-Value* } & \multicolumn{2}{|c|}{ With guidance } & \multicolumn{2}{|c|}{ Without } & \multirow[t]{2}{*}{$p$-Value } \\
\hline & $\mathrm{n}$. & $\%$ & $\mathrm{n}$. & $\%$ & & $\mathrm{n}$. & $\%$ & $\mathrm{n}$. & $\%$ & \\
\hline \multicolumn{11}{|l|}{ During RT } \\
\hline G1-G2 & $13 / 85$ & 15.3 & $38 / 90$ & 42.2 & 0.001 & $31 / 85$ & 36.5 & $48 / 90$ & 53.3 & 0.054 \\
\hline \multicolumn{11}{|l|}{ 2-Month FU } \\
\hline G1-G2 & $4 / 85$ & 4.7 & $6 / 90$ & 6.7 & 0.576 & $6 / 85$ & 7.1 & $8 / 90$ & 8.9 & 0.656 \\
\hline \multicolumn{11}{|l|}{ 6-Month FU } \\
\hline G1-G2 & $6 / 85$ & 7.1 & $1 / 90$ & 1.1 & 0.045 & $16 / 85$ & 18.8 & $11 / 90$ & 12.2 & 0.227 \\
\hline \multicolumn{11}{|l|}{ Last FU } \\
\hline G1-G2 & $4 / 85$ & 4.7 & $3 / 90$ & 3.3 & 0.643 & $25 / 85$ & 29.4 & $19 / 90$ & 21.1 & 0.206 \\
\hline
\end{tabular}

FU: Follow-up. *Chi-square test.

year MFS rates were $99.1 \%$ and $97.7 \%$, respectively, without statistical difference between groups.

Acute toxicities. During the treatment, grade 1-2 gastrointestinal (GI) toxicity occurred in 51/175 (29.1\%); grade $1-2$ and 3 genito-urinary (GU) toxicity in $79 / 175$ $(45.1 \%)$ and $2 / 175$ patients $(1.1 \%)$, respectively. At 2 months after RT, grade 1 GI toxicity was observed in $10 / 175$ patients (5.7\%), and grade 1-2 GU toxicity was observed in 14/175 patients $(14.0 \%)$. No grade 3 or more GU or grade 2 or more GI toxicities were recorded.

Grade 1-2 GI toxicity was significantly more frequent during treatment between patients treated without image guidance (Chi-square $p=0.001$ ); in contrast, no statistically significant difference was observed at 2 months after treatment completion (chi-square $p=0.576$ ) in terms of grade 1-2 GI toxicity. There was no statistically significant difference for grade 1-2 GU toxicity between patients treated with and without image guidance ( $p=0.054$ during treatment and $p=0.656$ after 2 months). Toxicity rates are summarized in Table II.

Late toxicities. At 6 months from the end of therapy, there were five cases of grade 1 and two of grade 2 GI toxicity $(4.0 \%)$, one treated without image guidance and six with (chi-square $p=0.045$ ). Grade $1 \mathrm{GU}$ toxicity was observed in 27 patients $(15.4 \%), 16(9.1 \%)$ treated with image guidance and $11(6.3 \%)$ without $(p=0.227)$. No grade 2 GU toxicity was recorded. Grade $3 \mathrm{GU}$ was reported in one case $(0.6 \%)$, treated with image guidance.

At the last follow-up, grade 1 GI toxicity was observed in three patients treated without image guidance and four with $(4.0 \%, p=0.643)$, and grade 3 in one $(0.6 \%)$ patient treated with image guidance. No grade 2 GI toxicity was noted. GU toxicity of grade 1 was observed in 36 and grade 2 in eight patients $(25.1 \%), 25(14.3 \%)$ treated with image guidance and $19(10.9 \%)$ treated without $(p=0.206)$. Data are summarized in Table II.

\section{Discussion}

At the beginning of the second millennium, Fowler et al. (5) created great interest in the role of hypofractionation for the treatment of localized prostate cancer. Thus, in 2004, we started a multi-institutional study using a HyRT schedule (60 Gy/20 fractions over 4 weeks) with the aim of reducing the total treatment time and in order to evaluate efficacy and safety of this regimen in patients with low risk prostate cancer. Our results demonstrated the efficacy of this hypofractionated schedule, reporting 5- and 8-year OS rates of $95.8 \%$ and $88.9 \%$, respectively. Five- and 8-year CSS rates were $100 \%$ and $95.4 \%$, respectively, with 11 patients $(6.3 \%)$ dying, nine $(5.1 \%)$ for causes not related to prostatic disease. The 5- and 8-year DFS were both $96.3 \%$ and the 5and 8-year bNED rates were both $93.2 \%$. Our results were favorably compared to other experiences of dose escalation using conventional fractionation regimens. Three randomized trials published long-term outcomes $(1,2,16)$. Zietman et al. reported a 5-year bNED rate of $91 \%$ and a 10 -year bNED rate of $84 \%$ (1). Kuban et al. reported 5 and 8-year bNED rates in low risk patients of $100 \%$ and $88 \%$, respectively (2).

Lee et al. reported results of a noninferiority phase II study in low-risk patients. Five-year OS, DFS and biochemical recurrence were $93.2 \%, 85.3 \%$ and $8.1 \%$, respectively, in the conventional RT arm $(73.8 \mathrm{~Gy}$ in 41 fractions), and $92.5 \%, 86.3 \%$ and $6.3 \%$, respectively, in the hypofractionated arm (70 Gy in 28 fractions biologically equivalent to $80 \mathrm{~Gy}$ in $2 \mathrm{~Gy}$ fractions assuming an $\alpha / \beta$ ratio of $1.5 \mathrm{~Gy}$ ) (16). This study demonstrated a noninferiority of 
HyRT instead of conventional radiotherapy, reducing the total treatment time by 2.5 weeks. In our study, reporting similar results, the treatment time reduction was 4 weeks compared to the conventional arm of the study of Lee et al. Other studies demonstrated that dose escalation, using conventional fractionation, reduced biochemical recurrence, but increased GI toxicity $(2,17)$. A hypofractionated highdose schedule was investigated by Patel et al. in a study which treated low- (72\%) to intermediate-risk patients with $66 \mathrm{~Gy}$ in 22 fractions (biologically equivalent to $84.9 \mathrm{~Gy}$ in 2 Gy fractions assuming an $\alpha / \beta$ ratio of $1.5 \mathrm{~Gy}$ ) with 5 - and 8 -year bNED of $97 \%$ and $92 \%$, and CSS of $100 \%$ and $98 \%$, respectively (18). We obtained similar outcomes with a treatment schedule with two fractions less.

In our study, patients treated with daily image-guided HyRT and a reduced margin of $5 \mathrm{~mm}$ from CTV to PTV presented a statistically better bNED and a trend toward a better DFS with respect to patients treated without image guidance with a larger margin. OS and CSS were not statistically significantly different. The better results in terms of bNED in patients treated with image-guided HyRT may be influenced by selection bias, considering the retrospective nature of our analysis, but of our data suggest that the reduction to $5 \mathrm{~mm}$ margin is safer in patients treated with image-guided HyRT. Moreover, patients treated with image-guided HyRT presented lower toxicity rates during treatment compared to patients treated without image guidance. In fact, $45.1 \%$ of patients presented grade 1-2 GU toxicity and $29.1 \%$ grade $1-2$ GI during treatment with statistically significant difference in GI toxicity between patients treated with and without image guidance $(15.3 \%$ vs. $42.2 \%, p=0.001)$ and a trend toward significance in term of GU toxicity $(36.5 \%$ vs. $53.3 \%$, $p=0.054)$. Two months after the treatment, the majority of patients had recovered from toxicities without difference between these two groups. Moreover, at the last follow-up, we reported low toxicity rates without statistical difference between those treated with and without image guidance.

Lee et al. reported grade 1-2 acute GI and GU toxicity rates of $42.2 \%$ and $58.9 \%$, respectively, in patients treated with hypofractionation without statistical difference respect to those treated with conventional fractionation (16). Our data are similar to their results in patients treated with HyRT, but better with respect to those treated with image-guided HyRT. Cumulative incidence of late grade 1-2 GI and GU toxicity were $40.6 \%$ and $54.6 \%$, respectively, with statistical difference between hypofractionated group and conventional treatment group. Patel et al. reported a good acute tolerance in patients treated with image-guided RT (ultrasound system), using $7 \mathrm{~mm}$ margin expansion from CTV to PTV, with $17 \%$ and $33 \%$ grade 1-2 GI and GU toxicity up to 90 days, respectively. At the last follow-up, grade 1-2 GU toxicity was $16.8 \%$, otherwise $92 \%$ of patients did not have any late GI toxicity (18). Our toxicities were similar to theirs, although they used a higher total dose. Dearnaley et al. in the CHHiP trial (19) reported grade 2 or more GI and GU toxicity of $2.3 \%$ and $7 \%$, respectively, in the conventionally treated group; $2.3 \%$ and $7.6 \%$, respectively, in the group of patients treated with $60 \mathrm{~Gy}$ in 20 fractions; and $0.8 \%$ and $7 \%$, respectively, in the group of patients treated with 57 Gy in 19 fractions assessed at 18 weeks after treatment start. No statistically difference in late toxicities was observed. Kupelian et al. using the same treatment schedule at that of the study of Lee et al. (with $4 \mathrm{~mm}$ rectal margin) reported $6 \%$ late grade 2 or more GI toxicity (8), while Martin et al. reported $6.3 \%$ using a treatment schedule like ours but with a PTV margin of 7-10 mm (20). At their last follow-up Kupelian and Martin reported a 5\% and 4\% GI toxicity, respectively, similar to our results. Arcangeli et al. reported final results of a randomized study comparing 62 Gy in 20 fractions and $80 \mathrm{~Gy}$ in 40 fractions. The rate of freedom from late grade 2 or more GI toxicity was $86.5 \%$ and $84.6 \%$ in the experimental and control arms, respectively, and $86 \%$ and $79 \%$, respectively, for GU toxicity (21).

Recently, technological development has led to the use of stereotactic body RT and extreme hypofractionation scheme (22) with a low rate of high-grade toxicities and high rate of tumor control. The most important criticism is that many patients with low-risk prostate cancer may not actually require any treatment and active surveillance may be a more appropriate initial strategy, especially in those with a low life expectancy (23). Comparative studies are mandatory.

Our study demonstrated that $60 \mathrm{~Gy}$ in 20 fractions for the treatment of patients with low-risk prostate cancer has efficacy in terms of OS, CSS, DFS and biochemical control. The treatment was well tolerated with a low incidence of high-grade acute and late toxicities. Patients treated with image-guided HyRT presented, during treatment, lower toxicity rates compared to patients treated without image guidance. Late toxicities were not statistically different between the two groups. Image-guided HyRT provided better bNED compared to unguided HyRT but had no impact in terms of OS and DFS. Therefore, reduction of margins from CTV to PTV with image-guided HyRT is safe.

\section{Conflicts of Interest}

Authors declare no conflict of interest.

\section{References}

1 Zietman AL, Bae K, Slater JD, Shipley WU, Efstathiou JA, Coen JJ, Bush DA, Lunt M, Spiegel DY, Skowronski R, Jabola BR and Rossi CJ: Randomized trial comparing conventionaldose with high-dose conformal radiation therapy in early-stage adenocarcinoma of the prostate: Long-term results from Proton Radiation Oncology Group/American College of Radiology 9509. J Clin Oncol 28: 1106-1111, 2010. 
2 Kuban DA, Tucker SL, Dong L, Starkschall G, Huang RH, Cheung MR, Lee AK and Pollack A: Long-term results of the M. D. Anderson randomized dose-escalation trial for prostate cancer. Int J Radiat Oncol Biol Phys 70: 67-74, 2008.

3 Swisher-McClure S, Mitra N, Woo K, Smaldone M, Uzzo R and Bekelman JE: Increasing use of dose-escalated external beam radiation therapy for men with nonmetastatic prostate cancer. Int J Radiat Oncol Biol Phys 89: 103-112, 2014.

4 Peeters ST, Heemsbergen WD, Koper PC, van Putten WL, Slot A, Bonfrer JM, Incrocci L and Lebesque JV: Dose-response in radiotherapy for localized prostate cancer: Results of the Dutch multicenter randomized phase III trial comparing 68 Gy of radiotherapy with 78 Gy. J Clin Oncol 24: 1990-1996, 2006.

5 Fowler J, Chappell R and Ritter M: Is alpha/beta for prostate tumors really low? Int J Radiat Oncol Biol Phys 50: 1021-1031, 2001.

6 Fowler JF, Toma-Dasu I and Dasu A: Is the $\alpha / \beta$ ratio for prostate tumours really low and does it vary with the level of risk at diagnosis? Anticancer Res 33: 1009-1011, 2013.

7 Thames HD, Bentzen SM, Turesson I, Overgaard M and Van den Bogaert W: Time-dose factors in radiotherapy: a review of human data. Radiother Oncol 19: 219-235, 1990

8 Kupelian PA, Willoughby TR, Reddy CA, Klein EA and Mahadevan A: Hypofractionated intensity-modulated radiotherapy (70 Gy at 2.5 Gy per fraction) for localized prostate cancer: Cleveland Clinic experience. Int J Radiat Oncol Biol Phys 68: 1424-1430, 2007.

9 Coote JH, Wylie JP, Cowan RA, Logue JP, Swindell R and Livsey JE: Hypofractionated intensity-modulated radiotherapy for carcinoma of the prostate: Analysis of toxicity. Int J Radiat Oncol Biol Phys 74: 1121-1127, 2009.

10 Ritter M, Forman J, Kupelian P, Lawton C and Petereit D: Hypofractionation for prostate cancer. Cancer J 15: 1-6, 2009.

11 Pollack A, Walker G, Horwitz EM, Price R, Feigenberg S, Konski AA, Stoyanova R, Movsas B, Greenberg RE, Uzzo RG, Ma $\mathrm{C}$ and Buyyounouski MK: Randomized trial of hypofractionated external-beam radiotherapy for prostate cancer. J Clin Oncol 31: 3860-3868, 2013.

12 Aluwini S, Pos F, Schimmel E, van Lin E, Krol S, van der Toorn PP, de Jager H, Dirkx M, Alemayehu WG, Heijmen B and Incrocci L: Hypofractionated versus conventionally fractionated radiotherapy for patients with prostate cancer (HYPRO): Acute toxicity results froma randomised non-inferiority phase 3 trial. Lancet Oncol 16: 274-283, 2015.

13 Hoffman KE, Voong KR, Pugh TJ, Skinner H, Levy LB, Takiar V, Choi S, Du W, Frank SJ, Johnson J, Kanke J, Kudchadker RJ, Lee AK, Mahmood U, McGuire SEand Kuban DA: Risk of late toxicity in men receiving dose-escalated hypofractionated intensity modulated prostate radiation therapy: Results from a randomized trial. Int J Radiat Oncol Biol Phys 88: 1074-1084, 2014.

14 Cox JD, Stetz J and Pajak TF: Toxicity criteria of the Radiation Therapy Oncology Group (RTOG) and the European Organization for Research and Treatment of Cancer (EORTC). Int J Radiat Oncol Biol Phys 31: 1341-1346, 1995.
15 Roach M III, Hanks G, Thames H Jr., Schellhammer P, Shipley WU, Sokol GH and Sandler H: Defining biochemical failure following radiotherapy with or without hormonal therapy in men with clinically localized prostate cancer. Recommendations of the RTOG-ASTRO Phoenix consensus conference. Int J Radiat Oncol Biol Phys 65: 965-974, 2006.

16 Lee WR, Dignam JJ, Amin MB, Druner DW, Low D, Swanson GO, Shah AB, D'Souza DP, Michalski JM, Dayes IS, Seaward SA, Hall WA, Nguyen PL, Pisansky TM, Faria SL, Chen Y, Koontz BF, Paulus R and Sandler HM: Randomized phase II noninferiority study comparing two radiotherapy fractionation schedules inpatients with low-risk prostate cancer. J Clin Oncol 34(20): 2325-2332, 2016.

17 Dearnaley DP, Jovic G, Syndikus I, Khoo V, Cowan RA, Graham JD, Aird EG, Bottomley D, Huddart RA, Jose CC, Matthews JH, Millar JL, Murphy C, Russell JM, Scrase CD, Parmar MK and Sydes MR: Escalated-dose versus control-dose conformal radiotherapy for prostate cancer: Long-term results from the MRC RT01 randomised controlled trial. Lancet Oncol 15: 464-473, 2014.

18 Patel N, Faria S, Cury F, David M, Duclos M, Shenouda G, Ruo $\mathrm{R}$ and Souhami L: Hypofractionated radiation therapy (66 Gy in 22 fractions at $3 \mathrm{~Gy}$ per fraction) for favorable-risk prostate cancer: Long-term outcomes. Int J Radiat Oncol Biol Phys 86: 534-539, 2013.

19 Dearnaley D, Syndikus I, Sumo G, Bidmead M, Bloomfield D, Clark C,Gao A, Hassan S, Horwich A, Huddart R, Khoo V, Kirkbride H, Mayles P, Naismith O, Parker C, Petterson H, Russel M, Scrase C, South C, Staffurth J and Hall E: Conventional versus hypofractionated high-dose intensitymodulated radiotherapy for prostate cancer: Preliminary safety results from the CHHiP randomised controlled trial. Lancet Oncol 13: 43-54, 2012.

20 Martin JM, Rosewall T, Bayley A, Bristow R, Chung P, Crook J, Gosporarowicz M, McLean M, Mènard C, Milosevic M, Warde P and Catton C: Phase II trial of hypofractionated imageguided intensity-modulated radiotherapy for localized prostate adenocarcinoma. Int J Radiat Oncol Biol Phys 69: 1084-1089, 2007.

21 Arcangeli G, Saracino B, Arcangeli S, Gomellini S, Petrongari MG, Sanguineti G and Strigari L: Moderate hypofractionation in high-risk, organ-confined prostate cancer: final results of a phase III randomized trial. J Clin Oncol 35(17): 1891-1897, 2017.

22 De Bari B, Arcangeli S, Ciardo D, Mazzola R, Alongi F, Russi EG, Santoni R, Magrini SM and Jereczek-Fossa BA; on the behalf of the Italian Association of Radiation Oncology (AIRO): Extreme hypofractionation for early prostate cancer: Biology meets technology. Cancer Treat Rev Nov 50: 48-60, 2016.

23 Cooperberg MR and Carroll PR: Trends in management for patients with localized prostate cancer, 1990-2013. JAMA 314: 80-82, 2015.

Received December 6, 2017

Revised January 15, 2018

Accepted January 18, 2018 